\title{
Information and Communication Technologies in the Daily Life of Elementary School Teachers: An Attitudinal Framework
}

\author{
Juan Carlos Ayala Perdomo \\ Universidad Autónoma del Estado de México \\ Anaid Pérez Monteagudo \\ Universidad Autónoma del Estado de México
}

Within the framework of the inclusion of Information and Communication Technologies (ICTs) in primary education classrooms in the City of Toluca, State of Mexico, this research proposes an analysis on the social construction of meaning that teachers make about technology. The focus is mainly on the universe of meaning in which teachers relate to technology, for which it is sought to obtain from teachers a story about how ICT is meant by them.

This communication deals in particular with the element that precedes the possible action and thought around any entity in the universe of meaning: attitude. For the formation of our attitude towards an entity, favorable or not, positive or negative, a previous representation of it is required. The analysis is developed under the structure of three general indicators: What do you think about the technologies? Do you like to use technologies in your daily life? and Do you like to work with technologies?

Keywords: technology, attitude, sense, teachers

\section{INTRODUCTION}

The common assumption surrounding technology is that of the existence of barriers that would sharply divide the generation gap between those who have learned and will want to continue learning, and those who have not learned and consequently refuse to at least try. The population of teachers interviewed shows that this attitude is neither overt nor rigid. What is certain is that it is always accompanied by an emotion: either of enthusiasm for learning, pride in what they have learned, hope for their potential, or fear and uncertainty about the risks involved, even in an abstract way, in the ICTs and their correct and incorrect uses.

These accounts, obtained through direct and personal interviews with all fifth and sixth grade elementary school teachers in three public schools in Toluca (26 teachers in total), are configured by means of three central theoretical categories: the attitude, competence and expectation of teachers in relation to ICTs in the general framework of their daily life, so that among the findings are the views that teachers have on issues such as what they are able to do with ICTs, what they expect from them for their educational work, but especially beyond it: in their daily life, at home, in their relationship with other people. 
For the majority, the opinion has been positive, and is even related to preference, to personal or collective enjoyment, but at the same time under conditions that will be specified for each indicator: what do you think of ICTs; do you like to use ICTs in your daily life; and do you like to work with ICTs?

\section{INDICATOR: WHAT IS YOUR OPINION ON ICTs?}

The category to be analyzed is the attitude that teachers express in relation to technologies in the more general area of their daily lives, without necessarily referring to their school life, although as will be seen in the evidence presented, teachers tend to place their opinions and beliefs in the context of three areas: school, home and work.

Hernández (Hernández Martín, 2008, p. 33) established that teachers' attitudes towards ICTs can be: positive, when they assume the innovation processes in which technologies are involved; and critical when the processes are slow or they are reluctant to the changes brought about by the integration of technologies in schools.

At the same time, she characterizes teachers according to their willingness to assimilate and act within the innovation processes:

a. The innovators, who integrate ICTs at an early stage

b. Those that integrate them in the medium term

c. Those who are slow to integrate them (in these last two classifications the delay is a matter of willingness to use the equipment, not its availability)

d. Those reluctant to change. (Hernández Martín, 2008, p. 33)

On the other hand, when it is considered that teachers have already internalized a positive attitude towards the technological environment and its possibilities, they end up taking on one of these roles:

a. Creative role: acting creatively and encouraging creative actions among their students.

b. Investigative role: when they are constantly reflecting on how to approach the curricular integration of the different media. (Hernández Martín, 2008, p. 43)

The interviews collected were not intended to characterize the teachers in one way or another, as it has been insisted that the search focuses on a moment prior to the presence of ICTs in the classroom, which would also require an observation exercise within the teaching dynamics of the schools.

But the intention of recovering these quotations from Azucena Hernández is to place the teachers' discourse on the indicators of opinion and preference for working with technologies in a framework that allows us to anticipate whether the meaning that teachers are socially constructing around technologies is oriented towards positive or critical attitudes, and if within the former there are elements in the "zero moment" of the meaning of ICTs to think of a context of innovative attitude in teachers, or if there is a middle ground between the integrative or reticent attitude, and for what reasons.

In order to better understand this search, we will begin by analyzing the question "What do you think about technologies?", under a categorization that emerges from the meaning of the answers given by the teachers interviewed.

When the attitude is positive, a statement that always accompanied this in the form of an opinion was the one that reflected a sense of omnipresence of ICTs, an allusion to the fact that technologies, besides being well valued, are present in every aspect of both work and daily life. With this and other arguments of the interviewees, it was possible to characterize the meaning of this positive opinion under four adjectives: 
TABLE 1

TEACHER'S PERCEPTION OF ICT

\begin{tabular}{|c|c|c|c|}
\hline EXCELLENT & VERY GOOD & FAVORABLE & ESSENTIAL \\
\hline $\begin{array}{l}\text { - Improves quality of } \\
\text { life } \\
\text { - Development of } \\
\text { competencies and skills } \\
\text {-Any invention is good }\end{array}$ & $\begin{array}{l}\text { - According to their } \\
\text { uses: With intelligence } \\
\text { - Safety } \\
\text { - -Because of their } \\
\text { omnipresence "all over } \\
\text { the world" "everyone } \\
\text { has them") } \\
\text { - Transcendent } \\
\text { possibilities of human } \\
\text { fulfillment } \rightarrow \\
\text { challenges, perspectives } \\
\text { - Different ways of } \\
\text { seeing and conceiving } \\
\text { the world }\end{array}$ & $\begin{array}{l}\text { - Projected benefit in } \\
\text { home/work } \\
\text { environments } \\
\text { - More time for the } \\
\text { development of specific } \\
\text { interests } \\
\text { - Tools } \\
\text { - Addressing situations }\end{array}$ & $\begin{array}{l}\text { - School element } \\
\text { - Cultural object } \\
\text { - Advancing science } \\
\text { - Support for disability }\end{array}$ \\
\hline
\end{tabular}

If we delve deeper into their statements, we can find a discursive reflexivity that nevertheless questions the sense of transcendence of technologies. This means that a positive opinion now does not express unconditionality in the future.

Just as potential for individual fulfillment and a different configuration of possible worlds are attributed to it, there is also a discursive framework in opinion, above all in that which is enunciated by teachers in their simultaneous role as parents, which is conflicted in the face of technology:

- ICTs as surrogate parents

- Content unsuitable for children

- The abandonment of values and social coexistence

- Risk due to content and online behaviors

- Potential of human replacement

These statements lead to the postulation of a category that is maintained as "positive" but is framed as neutralized: a good attitude towards technologies and a positive judgment about them. Significant conditioning factors weigh on their representations:

- Sense of invasiveness in the face of which ICTs are requested to provide more security.

- It modifies work, and although it makes it more practical, it requires better guidance for use (education, training), responsibility in the use of programs and topics.

- Need to create networks, in the broadest social sense of the term, and not the one reserved for internet networks, to improve teaching through ICTs.

When this reflexivity in the teachers' answers insists on the responsible and mature "management" of ICTs, it gives shape to the collective idea of objectifying where we want to go and what we want to achieve with ICTs.

Hence, it is necessary to refer to the "zero moment" of signification before venturing a characterization of teachers like the one mentioned above, since the will is positive, and the attitude can be asserted as innovative, but first it is necessary to approach the configuration of the universe of meaning in which the verification of uses in classrooms would be only one of the faces of a path that teachers have been walking along with technologies for longer in their lives than at school, and since ICTs have been included in the latter.

The interviews projected this tension between the positive attitude that is maintained towards innovation, and that with an argument based on delay or resistance, and in the last testimony the assertion of a philosophy draws meaning from the ideas about ICTs. 
Moving on to the opinions that make more explicit the negative aspects of technologies in the teachers' opinions, which would lead them to an attitude of resistance rather than resilience to technologies, they focus on the following aspects:

- Perception of fear: due to the substitution of the human, depersonalization, accentuation of the symbolic aspects of generational gaps.

- Dehumanization: the risks involved in the practice and shaping of ideology and of the frameworks of what is correct and desirable, the disregard for the contents and uses of technologies, as well as the enunciation of a "harmful" potential. However, on this point it is remarkable that these potential risks or damages are not specified in the statements, the empirical referents of what is considered "good" or "bad", of what "helps" or "harms" are not specified, which leaves an ambiguity regarding the symbolic universe and the sphere of practical actions from which teachers approach technologies.

An additional observation is that the imaginaries for both positive and negative opinions is that the imaginaries from which one can anchor an attitude in relation to ICTs are not staged at school, or at least not in a spontaneous way in the course of the interviews, although their responses do allude to what concerns school life.

The ideas that "everything would be better" or "everything would be worse" are found in other areas, especially in social and collective life, under the aforementioned spirit of human transcendence, but scarcely in the school. This may speak of a scarce work with technologies, which is not consistently sustained in their discourse, and rather speak of a meaning that remains contingent, ambiguous, open to multiple meanings in the "zero moment" of signification.

These other spheres of enunciation are stated in their enunciation under the following hierarchy, according to the emphasis placed on the relationship between ICTs and the following agents, the most prominent being the ego agent, the self.

TABLE 2

SIGNIFICANT RELATIONSHIPS BETWEEN ICT AND OTHER SOCIAL CONTEXT

\begin{tabular}{|l|l|}
\hline $\begin{array}{l}\text { The opinion about technology becomes } \\
\text { relevant in the relationship with: }\end{array}$ & In the role or context of: \\
\hline SELF & Personal / Mother or father \\
\hline HOME & Daily, everyday life \\
\hline WORK & Professional / Teacher / Institutions \\
\hline CHILDREN & Students / Generic \\
\hline
\end{tabular}

It is worth noting that with regard to the enunciation of the agent "children", the concerns associated with technologies may be symbolically distanced from the school, but not from the children as the main subjects affected by the negative attributes of ICTs.

To return to the idea of the roles of teachers assumed in relation to technologies, the discursive elements left by the interviews point to the fact that there is first an attitudinal predisposition towards the research role rather than the creative one, since for the time being there is more reflexivity than a creative possibility. And this is not because teachers are not creative (testimonies range from those who describe their culinary creations or handicrafts, to those who design using didactic application software), but because of the complexity of the already extensive process of inclusion of technology in the classroom, and the different experience that each teacher has had in relation to it due to the characteristics of their biography as a teacher and the configuration of their own communicational ecosystems.

As methodological learning in the recovery of these opinions, we propose the following matrix that condenses the recurrent aspects that shaped, from the different narratives and textual elements of the teachers, their perception and attitude towards technologies: 
TABLE 3

ELEMENTS OF OPINION ON TECHNOLOGIES

\begin{tabular}{|c|c|c|c|c|c|}
\hline REFERENCE & ENUNCIATION & JEVALUATION & $\begin{array}{l}\text { TEMPORALITY } \\
\text { OF OPINION }\end{array}$ & RELEVANCE & PERCEPTION \\
\hline $\begin{array}{l}\text { Concrete / } \\
\text { Abstract }\end{array}$ & $\begin{array}{l}\text { Objective / } \\
\text { Subjective }\end{array}$ & $\begin{array}{l}\text { Functional / } \\
\text { Moral }\end{array}$ & $\begin{array}{l}\text { For the present / } \\
\text { For the future }\end{array}$ & $\begin{array}{l}\text { From the subject } \\
\text { (Self in }>\text { Home } \\
\text { or School / From } \\
\text { the social (The } \\
\text { world > Near or } \\
\text { far; Present or } \\
\text { future / } \\
\text { Humanity) }\end{array}$ & $\begin{array}{l}\text { Positive aspects } \\
\text { (potentials } \\
\text { / reach / } \\
\text { progress) / } \\
\text { Negative aspects } \\
\text { (risks / } \\
\text { limitations) }\end{array}$ \\
\hline
\end{tabular}

\section{INDICATOR: DO YOU LIKE TO USE ICTS IN YOUR DAILY LIFE?}

For the indicator "Do you like to use technology in your daily life?" the narratives in the interviews were organized in principle under the two logical parameters of likes and dislikes, in which the associations with the three separate domains of home, work and school are also cross-referenced

From there, the issue becomes more complex, adding considerations about the categories of information, entertainment, moral evaluation and what I call displacement of the daily life. Regarding the "Likes" parameter in the work environment, the following is reported:

- The didactic application of ICTs (in terms of production of school materials and the reproduction of programs for didactic purposes)

- Practicality

- Efficient communication

- Functionality, which is associated with the factors of accessibility, connectivity, availability and adaptability

- Information portability

- Creative uses (in terms of designing, elaborating and innovating with ICTs, although, as mentioned above, this item does not manage to be objective, but is empirically evidenced in the textuality of the interview)

- Work uses (in terms of organizing, producing, researching, planning, for the purposes of school administration or for the performance of other tasks that teachers consider productive outside of school)

In this parameter circumscribed to work, information mediation stands out as something associated with a preference, and therefore a better predisposition to research, both for school purposes and for continuing education and the academic interest of the interviewees, as well as to learn and use applications (although only some teachers mentioned specific apps that allude to the characteristics of computers and mobile devices). For the same parameter of "Likes" but on a personal level, the following stands out:

That the mediation of entertainment linked to leisure and rest has an outstanding weighting to refer to what and why they like technologies. Here reference is made to listening to music, going to the cinema or having it at home, watching television, playing games and thus having a "pleasant", "enjoyable" life (although it has been noted that mentions of reading do not appear, and at this point it is worth saying that neither as a hobby).

Beyond the recreational retribution, the pleasure of technologies in everyday life is also associated with the availability and ease of combining family life with work life, by having at hand a presence of information, but above all of people, especially those dear to us, such as children or parents. In this gratification, not only 
ICTs, but also the most elementary domestic technologies are merited, under the argument that they facilitate tasks and free up time and relaxation to redistribute it with the family.

Other mentions of liking show processes of subjective internalization of technologies, understood as the assimilation of the possibilities and attribution of the subject's achievements to the subject himself, that is, an appropriation in which the positive attributes of the technologies become part of the self-perceived capacities.

Among these abilities is the ability to socialize content, which is marked first by family mediation rather than by the school. This is demonstrated by comparing the recurrence with which interviewees mentioned sharing information with their children, versus the much less frequent reference to seeking or sharing information of any kind with their students.

Another ability is to discover for themselves, "not to forget the outside", to keep the capacity to be amazed and in general to accept the learning and use of ICTs as a positive challenge, which favors them in their growth and the development of their daily life.

However, when daily life is mentioned, what is observed is a displacement, which is expressed in a difficulty in the verbalization of the interviewees to abstract the notion of daily life, on the one hand, and on the other hand, a persistence of the association of ICT with school in a first order of reflexivity, especially when exploring its productive meaning, its significance as a tool. It would seem that the school is their ordinary daily life, which could be addressed in another research that uses ethnography as a methodological strategy.

Under the parameter of "dislikes" in the teaching or labor field, what stands out is:

Resistance or resentment for the bureaucratic work associated with ICTs ("making charts or reports"), which is significantly linked to a sense of obligation, of doing things out of necessity rather than for pleasure. This leads to the elaboration of the idea of having to "relive" learning processes, a cognitive task that some teachers already perceive as distant in their habitus.

What the teachers who made up the study universe "dislike" on a personal level is:

- That ICTs represent a waste of time, a distraction.

- The mist of a generation gap that makes them feel outdated, surpassed by others based on their level of technological mastery. In this aspect, the older the age of the interviewees, the lesser the possibility of learning according to their own imaginary, although the reality they express is that their willingness to learn is greater than that of the younger teachers.

- The uncomfortable encounter between the generational adscription of belonging and seclusion ("my" generation - recurrent statement, meaning "adult") and that of the so-called "digital natives", which generates a conflict of discursivity that is expressed between those who "know" or "can" and those who do not.

- Frustration of finding learning caps, unexplored frontiers on both cognitive and practical aspects.

- The use of ICTs can sometimes be too individual or limited.

- Health problems due to the use of technologies (such as headaches), although this mention is marginal.

In general, it has been reiterated that there is no objectification of contents or possible uses of ICTs for the school, although reflection on them in this space is placed at the first of the explicit mentions. That is to say, school seems to be the daily routine, technologies are accepted as already being in the school, but very little is said about what they are, what can be done or learned from them, what contents or applications are liked or disliked, and what are the most important ones.

This leads to the methodological reflection on whether the teachers were unable, unwilling, or the researcher did not favor them to objectify the uses or contents imagined for the relationship between ICTs and school? 


\section{INDICATOR: DO YOU LIKE WORKING WITH TECHNOLOGIES?}

The possible barriers that can condition technological integration have been discussed by BECTA (2009), as well as by Mominó, Segales and Meneses (1994). It is recalled that they can be categorized under two general headings:

- External or first-order barriers

- Internal or second-order barriers

Next, we will analyze, by means of the indicator "Do you like working with technology?", which are some of the discursive elements that, on a symbolic level, guide the attitude of the teachers who made up the sample of this research towards some of these barriers.

This will not be done as the frameworks of these concepts assume, which is in the school and with the teacher in action or omission in the face of the technology already present, but from the assumption of a "zero moment" in its construction of meaning, which implies a first location of its narrative in the broader definitions of "preference" and "work".

In this context, by the way, I would like to mention that there is no teacher interviewed who does not feel happy to be a teacher, and that, leaving aside the hardships of exceptional work or the need to learn new skills or routines, they are extremely happy to be teachers.

They do like working with technologies because:

- They help them socialize.

- They bridge the generation gap, when the meaning of expressions ranging from "I have to" to "I like it" is communalized.

- Teachers learn from the young (their students), which suggests the beginning of what could be a bridge of collaboration between teachers and students, mediated by computers (but facing the constrictions of equipment availability and cognitive mediations previously discussed).

- They help them work and reduce the effort, in terms of producing and presenting materials and content suitable for their classes. Less "wear and tear" in preparing materials and "giving" class.

- Their children and pupils like technology. It generates motivation and excitement in children (referring especially here to the multimedia content of computers).

At this point, if the categorical statements were to be derived from these fragments of the story, the most complicated barriers could be assumed to have been overcome, according to the conceptualization of the authors cited at the beginning of this section, which are the second order barriers, since they imply: lack of confidence, resistance to change, negative attitudes, non-perception of the benefits and lack of access to personal resources. It can be seen that immersed in their will, expressed in different passages of the interview, attitudes or beliefs about how to teach, about computers, about teaching practices and about their willingness to change become positive.

But perceptions about the pleasure of working with technologies have their own particular nuances, demands that should not be read only from a supposed enunciation of resistance to change, or not believing in one's own skills or those of others, or ignoring the pedagogical possibilities of ICTs. These nuances have to do with a more complex construction of meaning that brings together both rational and emotional aspects, which are often guided by intuition and are generally configured under the concept that I postulate for culture: the universe of possibilities of meaning.

In this regard, teachers say that they like to work with technologies, but:

- Only creatively, when what they expect to be produced comes from their own conceptions and competencies. ICTs will reveal themselves positively in association with competencies, skills and contents, but not on their own.

- If the work is valued in relation to an individual qualification of competencies, skills and content mastery, and not for the technology itself. That is to say that the recognition is directed to them and not to the technological device.

- Expecting that personal and professional gratification is achieved as a function of the learning that was achieved.

- Also, that there be an anchorage to the school environment and not be left to a personal initiative that is often not accompanied by training that is self-assessed as sufficient or relevant. 
- Only if it becomes customary (then culture as just defined above)

Another question that makes it possible to think that second-order or internal barriers can appear or be broken down from the configuration of the "zero moment", that is, in the context of the universe of meaning that is related to the communicational ecosystem of teachers, is to recognize the attributes that teachers state in relation to their preference for working with technologies, by means of the keywords:

$$
\begin{gathered}
+ \text { Ease of use }+ \text { alternatives }+ \text { creativity }+ \text { bringing together experiences and imaginary }(\text { travel })+ \\
\text { getting used to }+ \text { classroom aids }+ \text { eye-catching }+ \text { attention }+ \text { information }+ \text { virtuality }
\end{gathered}
$$

The case of the mentions to Enciclomedia exemplifies the sequence that goes from "moment zero" to that from which the inclusion of ICTs in the classroom has been considered, which is the moment when the teacher already has them in the classroom and it is assumed that they already know how to use them, that they have understood and practiced them as a competence that accompanies them by the mere fact of being an elementary school teacher in Mexico.

The interviewees give a picture in which, before the arrival of Enciclomedia to their schools, the program had a positive evaluation, and they perceived a prevalence of resources and routines to which the program and its equipment would be integrated. After its implementation and exercise, teachers elaborate a narrative in which the program itself, or the cognitive and practical challenge it poses to them, leads to a perception of risk and fear of falling behind in their self-perceived competencies.

From these testimonies in general, and recovering Moscovici's definition of attitudes (Moscovici, 1984, p. 121) in which he identifies the affective components as favorable or unfavorable feelings; the cognitive components as judgments, beliefs, knowledge; and the conative components as the tendency to action; and these components oriented to a dimension of representation that does not correspond to common sense reasoning, we arrive at a formula in which I postulate that:

In order to create culture, as an expression of customs, traditions, rites or myths, one must start from a lived, constant and significant experience that is accompanied by a reflexivity that does not constitute it only from common sense. Then the attitude, as an orientation and way of doing in cultural practices will be not only reactive but reflexive and will be both rational and emotional.

Taken to the case of this research, this would ideally be expressed as:

$$
\text { Approach }+[\text { experiences }(+ \text { eye-catching) }]+[\text { imaginaries (+attention) }] \text { to the classroom }
$$

\section{CONCLUSIONS}

From the foregoing, the following findings on the meaning and significance displayed by the attitude of teachers in relation to ICTs should be highlighted.

An attitude that, despite the researcher's insistence that the teachers participating in the research should position themselves at the "zero moment", emphasizes the counterpart uses of ICTs in everyday life and at school, which are found in searches and downloads of information linked to creative possibilities, expert uses, selective filters of information and ways of linking them to specific teaching or learning tasks, evaluation or educational planning as similes of, for example, the responsibilities of planning and ordering at home.

Thus, we perceive an attitude governed by the uses of the informative possibilities of similar technical tools in everyday life and the educational context. As a hidden risk behind a proactive attitude are the searches and downloads of one- or two-dimensional content on commonly used websites and without rational criteria for tracking, selection, validation or contrasting. Therefore, both everyday and school uses do not transcend into applications, uses, downloads or specific developments in expert computer programs, uses of common software or expansion of language conditions or practical realization. The use of Power Point, Word and the transposition of information search as information production prevails. Searches are carried out in Google, not in specific pages.

Another topic of interest is the sense of community with which ICTs are understood, expressed in a valuation of collaborative and collegial work with teachers, although for most of them this is still a pending task, as well as, to a lesser extent, the potential for expanding social life through social networks with 
students. This sense of community with teachers and students would be homologous to socialization in daily life (such as at home) in terms of interaction oriented to the achievement of common goals, establishment of dialogues and exchange of experiences, help in bridging generational and cognitive gaps, affinity of interests, and safeguarding of job stability.

The symbolic weight of the school organization, the social prestige of the educational center, and to a lesser extent the students' impetus and self-management accompany the positive perception of the educational implication of ICT. This constitutes an aspirational imagination as subjective expressions of personal and professional fulfillment mediated by ICT. However, there are also institutional constraints, characterized as problems in the management and administration skills, which are similar to the representation of the processes of technological integration, especially as regards work, separated, as explained above, from the teaching activity proper.

In this regard, there are no concrete and specific conditions for the implementation of educational projects based on the teachers' and students' own initiative. However, there is also no notable resistance to the implementation of technological incorporation-integration programs.

Although in the minority, doubts are expressed about the unfeasibility of the permanence of teachers, written texts and books in the face of the presence and constant interaction with technologies. The counterbalancing argument is that teachers provide moral, affective and practical guidance that cannot be replaced by ICTs.

\section{ACKNOWLEDGEMENT}

Translated \& edited by American Publishing Services (https://americanpublishingservices.com/).

\section{REFERENCES}

British Educational Communications and Technology Agency. (2004). A review of the research literature on barriers to the uptake of ICT by teachers. London: Becta ICT Research.

Cabero, J. (2008). Tecnología Educativa (Educational Technology). Barcelona: Synthesis.

Camacho, C. (2009). Apropiarse de tecnología significativa: recaminando un andar (Appropriating meaningful technology: retracing a journey). In M. Paniagua \& Ú., Palos, Narrativas docentes en contextos innovadores (pp. 47-64)). Tlaquepaque: Instituto Tecnológico de Estudios Superiores de Occidente.

Cebrián de la Serna, M. (2008). La formación del profesorado en el uso de medios y recursos didácticos (Teacher training in the use of didactic media and resources.). In J. Cabero \& e. al, Tecnología educativa (pp. 131-149). Madrid: Synthesis.

Hernández Martín, A. (2008). La formación del profesorado para la integración de las TIC en el currículum: Nevos roles, competencias y espacios de formación (Teacher training for the integration of ICTs in the curriculum: New roles, competencies and training spaces.). In A. GarcíaValcárcel Muñoz-Repiso \& e. al, Investigación y tecnologías de la información y comunicación al servicio de la innovación educativa (pp. 33-55). Salamanca: Universidad de Salamanca.

Hooper, S., \& Rieber, L.P. (1995). Teaching with technology. In A.C. (Editor), Teaching: Theory into practice (pp. 154-170). Needham Heights, MA: Allyn and Bacon.

Ibáñez Salinas, J. (2008). Criterios generales para la utilización e integración curricular de los medios (General criteria for the use and curricular integration of the media). In J. Cabero \& e. al, Tecnología educativa (pp. 107-129). Madrid: Synthesis.

Leal, M., \& Arias, J.L. (2009). Práctica docente y tecnología en el aula (Teaching practice and technology in the classroom). Tlaquepaque: Instituto Tecnológico de Estudios Superiores de Occidente.

SEP. (n.d.). Plan Sectorial de Educación 2007-2012 (Education Sector Plan 2007-2012). Portal de la Secretaría de Educación Pública, Gobierno Federal. Retrieved January 2010, from www.sep.gob.mx 